\title{
Small and Medium-Sized Enterprise Information Construction Research Based on Cloud Computing
}

\author{
Zhao Rui-jie, Tang Li-chun \\ School of Business Administration, South China University of Technology, Guangzhou, China
}

Email address:

bangbangtangzhile@163.com (Zhao Rui-jie)

\section{To cite this article:}

Zhao Rui-jie, Tang Li-chun. Small and Medium-Sized Enterprise Information Construction Research Based on Cloud Computing. Journal of Investment and Management. Vol. 5, No. 5, 2016, pp. 45-50. doi: 10.11648/j.jim.20160505.12

Received: August 10, 2016; Accepted: August 22, 2016; Published: September 10, 2016

\begin{abstract}
The small and medium-sized enterprises occupy the important position of the Chinese economy in the quantity and the contribution to the economy. Due to the shortage of funds, lack of technology and the lack of professional talents, small and medium-sized enterprises are facing the bottleneck of information construction. Therefore this paper puts forward a cloud service model in the information construction. This paper compares the differences between cloud computing and traditional patterns in the aspects of stability, flexibility, cost, and security. The practical significance of the cloud model is also discussed. Cloud model can improve the operational efficiency of the existing equipment, reduce the initial investment and operating costs, including management, update, and reduce the overall cost of the user. Finally, verify the cost advantage of information construction by using the actual data of small and medium-sized enterprises. Cloud model in two aspects of software cost and service cost advantages. Thus, we provide a new way to solve the bottleneck of information construction in small and medium-sized enterprises.
\end{abstract}

Keywords: Cloud Computing, Small and Medium-Sized Enterprise, Information Construction

\section{Introduction}

The data statistics show that China's small and medium enterprises accounted for more than $90 \%$ of the total number of enterprises, and occupy an important position in the national economy. The average life span of small and medium-sized enterprises is very short, and the period is 2.5 years [1]. The work of [2] collected more than one thousand small and medium-sized enterprises research data in six cities, and pointed out that the majority of the small and medium-sized enterprises facing the problem of insufficient funds and low degree of information technology [2]. The advantage of cheap labor is gradually disappearing. The degree of information technology of small and medium-sized enterprises directly affects the modernization process of the national economy. The author of [3] conducted a longitudinal study of 100 enterprises in three consecutive years. The information input and the current operating income as variables, do regression analysis. It is found that the investment of enterprise information has a positive effect on the growth of profit and innovation. The work of [4-7] pointed out that, in addition to the information construction can reduce corporate communication and coordination costs, but also effectively improve the competitiveness of enterprises, operating costs and production performance.

Due to the traditional model of information construction required huge capital, large enterprises forming "monopoly advantage". It seriously affected the long-term development of small and medium-sized enterprises and even the entire national economy IT information construction process. So small and medium-sized enterprises development information construction is imperative. Currently, the information construction of small and medium-sized enterprises is blocked, and the characteristics of cloud computing services just meet the needs of small and medium-sized enterprises. Give new opportunities and challenges.

The National Institute of standards and Technology (NIST) defines cloud computing as a pattern of pay per use. This model provides the available, convenient, on-demand network access. Access to configurable computing resource pools (resources, including networks, servers, storage, applications, and services) that can be quickly provided. As shown in Fig. 1, simply put in a very small amount of management, or interact with a service provider. You can get it. Cloud computing's goal is to improve the processing power of the cloud computing 
provider and reduce the burden on the terminal processing, so the user side is simplified into simple input and output devices. This model is also known as the IT infrastructure, like water and electricity.

Cloud computing is a kind of IT service. According to the mainstream of service type is divided into three categories [8]: IaaS (infrastructure as a service) provides basic computing, data storage, operating systems, and other services; PaaS (platform as a service) provides for application software development, testing, implementation of tools or platforms. Users can develop on a unified platform and run their own applications; SaaS (software as a service) providing application software and application system services, users can order or even free use of services, such as Baidu Cloud.

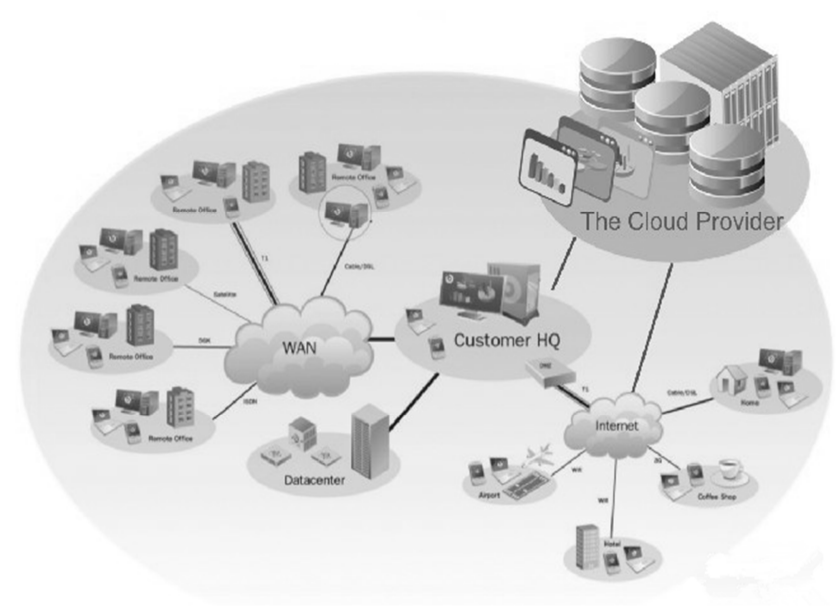

Fig. 1. Cloud computing

Cloud computing application model is called cloud model for short. The concept of "cloud computing" is now widely used in the production environment. Foreign countries have been very mature with IBM and Intel and the domestic "Ali cloud". Nowadays, there is little research about the application of cloud computing in the small and medium-sized enterprise informatization. Most of it is to put forward a concept; the specific application of research, as well as the case of the data research is obviously insufficient. Therefore, this paper discusses the practical significance of the cloud model, and uses the actual data to verify the analysis.

\section{Present Situation of Small and Medium-Sized Enterprises Information Construction}

\subsection{Low Level of Information}

The quantity of small and medium-sized enterprises increases gradually, and it also has a great influence on the growth of national economy. The advantages of small and medium-sized enterprises relatively large enterprises are small scale, and investment is not big and relatively flexible. [9-10] pointed out that due to financial and technical constraints,
China's small and medium-sized enterprises information construction are still in a relatively backward state. The overall level of information technology is less than $60 \%$. To solve the problem of small and medium-sized enterprise is no delay. In today's economic globalization, large enterprises having advanced IT technology, the first to establish a high level of information management system, greatly improving the management level and the efficiency of the operation of the enterprise.

\subsection{Information Construction Blocked}

Small and medium-sized enterprises' average life expectancy is very short, in order to achieve sustainable development in the competition, which requires small and medium-sized enterprises in the management and investment is very cautious. In order to improve the low level of the competitiveness of enterprises and improve enterprise's information management level requires more information management system input-output ratio, the higher the better. In the face of these problems, small and medium-sized enterprises in order to return the funds in the short term will certainly focus on reducing the initial investment and operating costs. Due to the lack of software and hardware facilities, network technology, lack of funds and professional personnel, enterprise information construction although can improve enterprise management level and operational efficiency, but the traditional mode of information construction input-output ratio is not optimistic [11].

Information construction requires per-acquisition of servers, software and other fixed assets. Post operation and maintenance costs accounted for more than half of the total investment, and the need for professional personnel to support. Common operating costs associated with the infrastructure are as follows:

- The required technical personnel in order to ensure that the environment is running;

- To maintain and strengthen the security and access control measures for the protection of facilities resources;

- Periodic updates and patches cost;

- For tracking the required permits.

In addition small and medium-sized enterprises information demand is not stable.

\subsection{Capacity Planning}

Capacity is within a certain period of time, the maximum amount of work to be provided by the information infrastructure. Enterprises need to build the information construction to meet the requirements of the largest, such as CPU, storage, computing resources. The difference between the capacity and the demand of IT resources will lead to the low efficiency of the system or the allocation cannot meet the demand. But the needs of the enterprise are not the same all the time. For limited funds small and medium-sized enterprises is undoubtedly a burden. It can potentially inhibit the response capabilities, profitability and overall development of the enterprise. Enterprises urgently need an 
innovative model to break the deadlock.

\section{Characteristics of Information Application in Cloud Model}

The required IT device is provided and managed by the third party cloud computing operator. Cloud computing is remotely providing services, primarily providing back-end processing capabilities and user based access to these capabilities. Not only the equipment safety, but also has the management personnel, can the specialized guarantee data security, the reliability, the system runs stably. Small and medium-sized enterprises do not need to be equipped with professional and technical personnel; the staff of a simple computer operation can be used.

\subsection{High Efficiency}

Using the cloud model, the system operation and maintenance by the supplier to complete, can ensure the stability of the system to run. Enterprise employees at any time, any place, any of the terminals can be shared resources. Save time and travel costs, greatly improve the efficiency of the work. Cloud computing can also make large scale modeling and data statistics in a very short period of time to complete. The efficiency of the original work is reduced by calculating the original work station alone. The calculation time is shortened and the work efficiency is improved.

\subsection{Low Cost}

Cloud model does not require companies to purchase high-performance hardware and software facilities, as well as the late operation and maintenance management. Just pay a small amount of use fee to get the same service. According to the need to purchase the right to use, enterprises in the early stage of investment in fixed investment and operation of the latter into the operation of the operation of funds. If you consider the time value of funds, then, for the enterprise is a savings.

Cloud computing to ownership, size and access to the division, can be divided into Public cloud. Community cloud, Private cloud and Hybrid cloud. The public cloud is a cloud environment that is owned by third party providers for public access. Relative to other is the cheapest, but also the most suitable for small and medium enterprises. But security is an important reason to hinder the public cloud, which will be described in the following section.

2014 Ali cloud lead down the price, Amazon, Google, Microsoft, and other companies have greatly reduced the price of cloud computing. With the reduction of cloud computing prices, the cost advantage of cloud computing are more prominent. In addition, cloud computing has a lot of network externalization. Because, cloud computing provider focus on the construction cost of the initial investment, and the majority of which is sunk costs. The use of more users will form a strong scale effect, the lower the marginal cost and the price will decline further.

\subsection{Flexibility}

From the point of view of IT resources, scalability refers to the ability to increase or reduce the use of IT resources can be processed. Cloud computing has the ability to expand and shrink with the needs of customers at any time. It can meet the demand of different stages sizes so it has a great flexibility. This makes the enterprise can be based on demand fluctuations and peak to automatically or manually expand or release IT resources. In addition, small and medium-sized enterprises funding constraints, this way can improve the liquidity of small and medium-sized enterprises funds, to make up for the shortage of funds and improve the competitiveness of enterprises.

Enterprise can be the entire information construction framework in the cloud computing IaaS; this model is more suitable for the establishment of new and low degree of information technology companies. Can also be built on the platform in the cloud PaaS, more suitable for the company has been put into the information construction. If you hold a conservative attitude to the cloud, you can rent a number of software for cloud computing SaaS which enterprise need to hire; will not change the original information structure of the enterprise.

\subsection{External Effect}

Enterprise cloud model inputs can make it more flexible and efficient, professional external package to enable enterprises to focus more on the core business. Small and medium-sized enterprises facing the market is relatively unstable, the funds are relatively tight, so the cloud computing brings the most significant impact on its flexibility [12]. Make the total flexibility brought about by the income expressed as (1):

$$
P=(M C+M B) \times N+\frac{D}{L}
$$

$\mathrm{P}$ is the cloud model to the enterprise bring high efficiency to focus core business revenue; $\mathrm{MC}, \mathrm{MB}$ standard that the marginal cost of reduced volume and marginal revenue; $\mathrm{N}$ for the annual output of products or services; L is cloud model flexibility brings benefits; D said no cloud model is used in revenue; F said scale enterprises. Different industries and different companies are not the same numerical value, so this paper does not do in-depth study of network's externalization.

\section{Comparison of Traditional Mode and Innovation Model}

\subsection{The Comparison of Two Models Feature}

According to a survey shows in the Fig. 2 that the attention degree of the enterprise for cloud computing technology and data security reach $96 \%$, the cost of attention $94 \%$.

Cloud computing in order to achieve commercialization in 
the small and medium-sized enterprises must be due to its high performance, low cost of ownership (TOC) and reliable security. The stability, flexibility and ease of use of the traditional network information and cloud computing are compared in Table 1. Security will be talked in next section. A hallmark feature of cloud computing is the ability to provide a wide range of inherent capabilities, which can enhance the availability of IT resources. Higher availability of cloud computing has longer service duration.

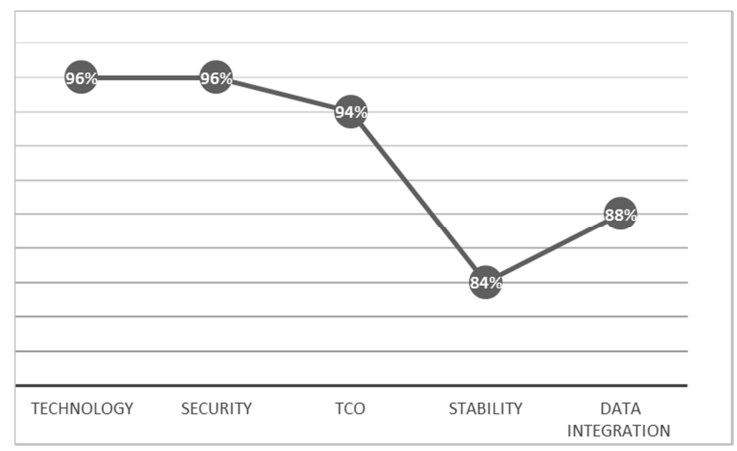

Fig. 2. Enterprise's attention to cloud computing.

Table 1. Two model performance comparison.

\begin{tabular}{|c|c|}
\hline \multicolumn{2}{|l|}{ Stability } \\
\hline Cloud model & $\begin{array}{l}\text { The availability of cloud computing up to } 99.95 \% \text { and the reliability of the data is not less than } 99.999 \% \text {. Data recovery will be more } \\
\text { convenient. }\end{array}$ \\
\hline $\begin{array}{l}\text { Traditional } \\
\text { mode }\end{array}$ & $\begin{array}{l}\text { The reliability of traditional server is limited by hardware. Prone to problems, need to manually back up. Artificial data recovery } \\
\text { difficult, time consuming. }\end{array}$ \\
\hline \multicolumn{2}{|l|}{ Elastic } \\
\hline Cloud model & $\begin{array}{l}\text { According to the need to configure CPU, memory and bandwidth. Can Upgrade at any time and without loss of data. Service pause time } \\
\text { can be controlled. }\end{array}$ \\
\hline Traditional mode & $\begin{array}{l}\text { Fixed configuration, it is difficult to meet the needs of various types. Change the configuration to hardware upgrades, cycle length } \\
\text { service stop time is not controllable }\end{array}$ \\
\hline \multicolumn{2}{|r|}{ ( } \\
\hline Cloud model & Rich operating system and application software, through the mirror can be a key to a simple deployment. \\
\hline Traditional mode & Almost no software is available to support the new server. Need to manually repeat all deployment operations \\
\hline \multicolumn{2}{|l|}{ Extensible property } \\
\hline Cloud model & $\begin{array}{l}\text { Seamless convergence of cloud products, sustainable business development to provide a complete computing, storage, security and } \\
\text { other solutions. }\end{array}$ \\
\hline Traditional mode & $\begin{array}{l}\text { It is difficult to find a complete service within the same service provider. Cannot guarantee the extensible and sustainability of business } \\
\text { growth. }\end{array}$ \\
\hline
\end{tabular}

Cloud computing is more stable than the traditional model, simple and easy to operate, with a strong flexibility and extensible property. Data survey shows that the traditional mode of information under the overall cost of ownership in the hidden service costs as high as 70\% [13].

\subsection{The Analysis of Cost}

In order to make the view more convincing, this paper extracts a traditional model has been transformed into a cloud model of small and medium-sized enterprises in the deployment of the data as a research case. As shown in Table 2 is a small and medium-sized service enterprise in the implementation of the cloud model before and after the investment situation [14]. Because the investment of traditional mode is mainly concentrated in the early stage, while the cloud model is the investment funds dispersed investment. In order to better compare the real difference between the two models costs, based on the existing data, the use of cash flow knowledge, and these two models of investment funds are converted into annual values for comparison.

Table 2. Investment cost information of a small and medium-sized enterprise.

\begin{tabular}{lll}
\hline & Before & cloud \\
\hline Hardware & PC server Switch & Switch \\
Software & SQL Server Weblogic operating system & Operating system \\
Software application & Purchase ERP applications (200 thousand RMB) & Rental cloud services (\$35/month) \\
Software service & Own management and operation & Cloud computing provider \\
Labor cost & Information center 15 people 4000RMB/M·P & Information center 5 people 5000RMB/M·P \\
\hline
\end{tabular}

* Time value of capital $(\mathrm{i}=5.6 \%)$

When considering the time value of the funds, the cost of hardware, software costs, service costs and labor costs are converted into adult costs, compared with the cost of the traditional model. Can be seen from Fig. 3, compared to the traditional model, the service cost savings is the most obvious, followed by the software costs. Manpower cost saving will take time to achieve. Because the cloud model provides one-stop professional services, do not need too much investment in the late. 


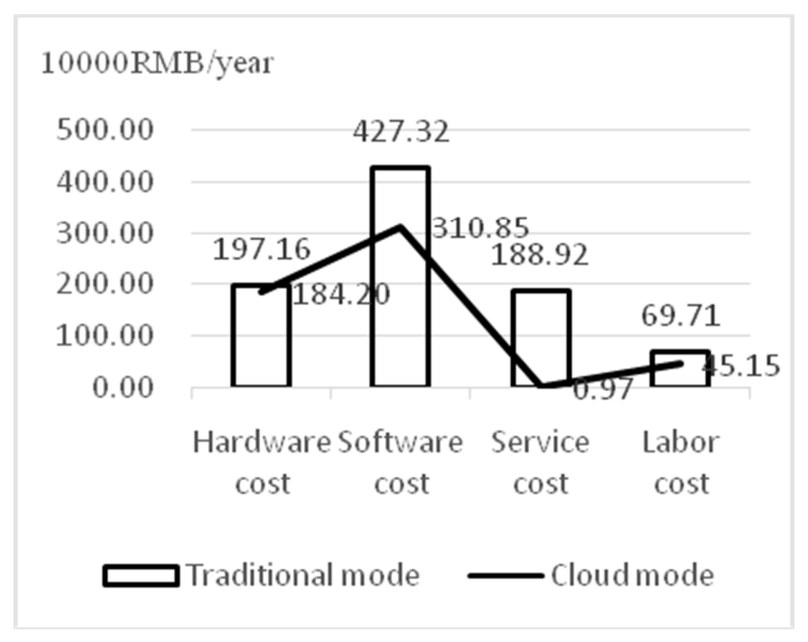

Fig. 3. Two mode cost comparison.

\section{Security Thinking}

Security has long been the main factor that cloud computing commercialization is questioned [15-17]. Enterprise Lass Bitg support for a project to get the data show that, taking the security issues, there are $1 / 2$ on top of the large enterprises and the small and medium-sized enterprises $1 / 3$ to postpone the use of cloud computing. Alibaba's chief technology officer, Dr. Wang Jian in the report "Internet, Cloud Computing and Data" also pointed out that at present, most of the enterprises because of security issues on the use of cloud computing services to wait-and-see attitude, which is a transformation of the mode of thinking of the process.

Cloud computing security must rely on the government to do a good job in the macro-control. The author [18] pointed out that the EU as early as 2009, the United States in 2010, Australia in 2012 developed a cloud computing security standards. They are not only in the leading position in technology; in the security management has also made great achievements. China in 2013 issued a public platform for e-government services, operation and maintenance, security and other aspects of the problem. In 2014, cloud computing may face the main security cover; put forward the basic requirements of safety management. In 2015, the government introduced a guide to the procurement of cloud services. In recent years, the government has begun to attach importance to the issue of cloud computing security norms

The way of centralized management in the cloud model is easier to upgrade security measures; security is higher than the PC era. Hacker attacks also exist before the cloud computing, and in recent years, the cloud service providers for security issues have made no small achievements. Such as Ali cloud institutional awareness of the core function is vulnerability scanning and intrusion monitoring; Server-Security is to protect the security of the login, checking and killing Trojan horse, patch management, safety inspection, web attacks to intercept and secure firewall; Web application firewall to prevent data leakage, defense malicious CC attack, to avoid web Trojan tampering and virtual patch repair buildings equal. Different companies can accord the different needs to purchase of cloud products to protect security. The author of [19-21] pointed out that the use and service of enterprises is more advantages than disadvantages, but also the modern enterprise is the inevitable trend.

\section{Conclusion}

This paper starts from the predicament of small and medium-sized enterprises information construction, and points out the new opportunity of small and medium-sized enterprises information construction -cloud model deployment. The application of cloud model in information construction makes up the shortage of funds and professional technology. This mode effectively promotes the process of informatization construction, so as to boost national economic construction. In the case of considering the time value of funds, comparing the difference between the traditional model and the cloud model, cloud model in stability, flexibility and security is advantage. In addition, the actual data also verify that the cloud model has a cost advantage in the overall. Especially in the two aspects of service costs and software costs are the most obvious. Cloud model is more in line with the characteristics of the development of small and medium-sized enterprises. Security is an important factor to hinder the enterprise adopting cloud computing. With the progress of science and technology, there has been a very successful case abroad. The government introduced the relevant cloud computing security standards, and can learn from the experience of developed countries. Cloud computing services security "position landing" is not something that cannot be achieved. The use and service of enterprises is more advantages than disadvantages.

When adopting the cloud model, the enterprise should pay attention to the monitoring of software investment and service input, and it is the direction of future research.

\section{References}

[1] Liu Guoping, Zheng Yanbing. Research on the solutions and key technologies of small and medium enterprise cloud services [J]. Telecom Science, 2013, 09: 37-43.

[2] Liang Bing. Research on the development of small and medium sized enterprises and its financing situation in China [J]. Financial Research, 2005, 05: 120-138.

[3] Dong Qi. How far is the road to information innovation of Chinese enterprises? -- An Empirical Research Based on the panel data of electronic information enterprise [J]. Management World, 2013, (07): 123-129+171.

[4] Wang Miaojun, Zhang Weiying, Zhou Lian. Information, organizational behavior and organizational performance: An Empirical Study Based on the Zhejiang enterprise [J]. Management World, 2007, (04): 96-104+129+172.

[5] Wang Miaojun, Zhang Weiying, Zhou Lian. Performance and influence factors of enterprise informatization investment: Empirical Evidence from Zhejiang enterprises [J]. China Social Science, 2007, (06): 81-93+206. 
[6] Wang Miaojun, Zhang Weiying, Zhou Lian. Information technology, organizational change and production performance -- An Empirical Study on the complementary mechanism of enterprise informatization [J]. Economic Research, 2006, (01): 65-77.

[7] Tan Z, Zhou W. The impact of enterprise information technology construction on enterprise cost [C]// International Conference on Service Systems and Service Management. IEEE, 2014

[8] Kashif U A, Memon Z A, Balouch A R, et al. Distributed Trust Protocol for IaaS Cloud Computing [C]// IEEE, International Urban Conference on Applied Science \& Technology. 2015: 275-279.

[9] Zhang Zeling. Cloud computing -- the construction of informatization of small and medium sized enterprises [J]. Opportunities and Challenges in Operation and Management, 2014, 02: 115-118.

[10] Zhang Qichen. Based on the "cloud computing" of the small and medium-sized enterprise accounting information new orientation [J]. Modern Economic Information, 2013, 22: 198-199.

[11] Yao Yanping. Research on the development of information construction and development of small and medium enterprises under the cloud computing [J]. Technology Innovation and Application, 2015, 10: 85.

[12] Liu Sen. The investment return rate of enterprise cloud computing information [J]. China Science and Technology Forum, 2014, No. 21806: 83-87.

[13] Lin Lili. Study on the application model of cloud computing in accounting informatization of small and medium enterprises in our country [D]. Institute of Fiscal Science of the Ministry of Finance, 2014.
[14] Xu Jie, Yao Rui. Enterprise Cloud Computing investment cost monitoring algorithm $[\mathrm{J}]$. Computer Engineering and Science, 2014, v.36; No.23507: 1244-1249.

[15] Chowdhury A, Tripathi P. Enhancing cloud computing reliability using efficient scheduling by providing reliability as a service $[\mathrm{C}] / /$ Parallel, Distributed and Grid Computing (PDGC), 2014 International Conference on. IEEE, 2014: 99-104.

[16] Xiang, Tan, Bo. The Issues Of Cloud Computing Security In High-Speed Railway [J]. Electronic \& Mechanical Engineering \& Information Technology International Conferee, 2011, 8: 4358-4363.

[17] Muthu Ramachandran. Software Security Requirements Management as an Emerging Cloud Computing Service [J]. International Journal of Information Management.

[18] Zhang Xiaojuan, Guo Juan. The construction of foreign government cloud computing security standard and Its Revelation [J]. E-government, 2016, No.16004: 83-90.

[19] Cheng Mengyao, Poremba. Sue security will kill the future of cloud computing $[\mathrm{J}]$. Software and Information Services, 2014, 10: $54-55$.

[20] Ali M, Khan S U, Vasilakos A V. Security in cloud computing: Opportunities and challenges [J]. Information Sciences, 2015, 305: 357-383.

[21] Rao R V, Selvamani K. Data Security Challenges and Its Solutions in Cloud Computing [J]. Proceed Computer Science, 2015, 48: 204-209. 